[Jones, E. (2001). Portfolio Assessment as a Means of Professional Development. New Zealand Annual Review of Education, 10, 187-202]

\section{Portfolio Assessment as a Means of Professional Development}

\section{ELIZABETH JONES}

\section{Abstract:}

Pivotal to the implementation of the Special Education 2000 policy are 750 Resource Teachers: Learning and Behaviour (RTLB). A mandatory requirement for those taking up these positions is that they undertake a professional development programme consisting of four graduate or postgraduate papers. This article outlines the rationale for including a professional practice portfolio as the final paper in this programme. The requirements of this portfolio and the teaching programme put in place to support the RTLB in the development of their portfolios are outlined. Some early findings about the process, from both RTLB and faculty perspectives, are then discussed. Findings indicate some of the factors that may help or hinder portfolio development, and also identify how portfolio development enhances professional practice.

$\mathrm{I}$

a recent article, Ruth Sutton describes how 200,000 English teachers spent their holiday preparing a six page portfolio to provide evidence of their teaching capability (Sutton, 2000). The reason? A $£ 2000$ pay rise! From its first appearance in teacher education in the 1980s, portfolio assessment has gathered momentum during the last decade. Portfolios are now becoming widely used in teacher education programmes in the USA (Lyons, 1998), Australia (Retallick \& Groundwater-Smith, 1999) and New Zealand (Ladbrook \& Middleton, 1997). The proliferation of portfolio assessment in tertiary education is evidenced by Anderson and DeMeulle's (1998) report on a survey of 24 universities that were using portfolios in their teacher education programmes. Portfolios are also widely used in the United States in the credentialing process for teachers and in professional development programmes (Wolf, Lichenstein \& Stevenson, 1997). Primary and secondary schools, too, are now frequently including student portfolios in their assessment strategies. Portfolios have become ubiquitous in education.

In late September, 2000 the first cohort of about 300 Resource Teachers: Learning and Behaviour (RTLB) submitted a professional practice portfolio to demonstrate that they had met the learning outcomes of the two-year professional development programme they had been undertaking. This programme, delivered by a consortium of three universities, Auckland, Waikato and Victoria University of Wellington, is a mandatory requirement for teachers accepting the RTLB positions created by the Special Education 2000 policy. The programme, consisting of four graduate or post-graduate papers, of which the fourth is the portfolio, leads to a graduate or post graduate diploma in special needs resource teaching.

RTLB provide support to students with mild to moderate learning and behaviour needs, and their teachers. Many of the teachers taking up these new positions have worked in previous special education positions (e.g., guidance and learning teachers, resource teachers of special needs, assessment class, special class and experience class teachers). The RTLB role involves significant changes in service delivery for many of these teachers. This change reflects a paradigm shift in special education from a functional limitations perspective that conceptualises special education needs as arising from a deficit in the student, to an inclusive perspective that conceptualises such needs as arising from a mismatch among the characteristics of the student, the requirements of the programme and the instructional environment experienced by the student. RTLB, working within the inclusive paradigm, work as collaborative consultants to support their teaching colleagues to make changes to the curriculum, teaching practices and school systems to meet the needs of students (Glynn, 1998). The nature of the work of the RTLB is indicated by the graduate profile for which the professional development programme is designed. On completion of the programme RTLB are expected to:

1. Work to a high professional and ethical standard;

2. Recognise and promote the bicultural nature of the New Zealand education system;

3. Work to ensure equitable educational opportunity for all learners;

4. Follow an educational model;

5. Work to a collaborative consultation model;

6. Be skilled practitioners and promoters of effective teaching skills;

7. Be reflective practitioners. 
The content of the first three papers of the programme addresses the above outcomes, each paper having a particular focus. Paper One focuses on students in their cultural, family and learning contexts. Paper Two focuses on the classroom ecology and strategic and inclusive teaching practices. Paper Three focuses on school-wide and community issues and interventions. Paper Four requires the RTLB to develop and submit a portfolio that demonstrates their competence in the seven learning outcomes across the three foci of the preceding papers (Glynn, 1998).

This article will outline the rationale for including a portfolio as the final paper in the programme. The requirements of this portfolio and the teaching programme put in place to support RTLB in developing their portfolios will be outlined. Some interim findings about this process from RTLB and faculty perspectives will then be discussed.

\section{Rationale}

The portfolio was selected as the culminating assessment task as a means of promoting the transformation of learning on the programme into the practice of RTLB. If RTLB are to work effectively and consistently in the inclusive education paradigm, there is need for constant reflection on their role in promoting an equity pedagogy, while they are often working in classrooms and schools where practices are predicated on the functional limitations paradigm. Particular challenges RTLB face, both in terms of their personal beliefs and those of the colleagues with whom they work, arise in relation to the bicultural partnership between pakeha and Maori as outlined in the Treaty of Waitangi, the requirement of the New Zealand Curriculum Framework (1993) that the curriculum must be accessible to all learners, and the goal of SE2000 that New Zealand develop a world class inclusive education system. Such issues require RTLB to be able to examine their practice in light of the power relationships in the contexts in which they work. For many RTLB undertaking the training, significant shifts are called for, both in their thinking and in the way they work. The consortium was seeking a tool for this.

Ecclestone (n.d.) proposes a theoretical framework of learner autonomy and assessment that links the three types of learning transmission, transaction and transformation - with three levels of learner autonomy - procedural, personal and critical autonomy. Procedural autonomy is related to the transmission of specific knowledge and processes to the learner. Assessment tasks that promote such autonomy tend to emphasise the replication of predetermined information. Ecclestone suggests that procedural autonomy may be pre-requisite or co-requisite to personal and critical autonomy. Personal autonomy occurs through learners' reflection on their professional practice and search for self-knowledge. Transactional learning enables learners to engage in self-evaluation and to consider their practices from an ethical standpoint. Critical autonomy is achieved when learners are able to "go beyond an awareness of their procedural strengths and weaknesses, or preoccupation with personal attributes, to the ability to appraise their position in relation to a much broader context." Learners are able to reflect on the socio-political context in which they work and the role they play in it. Ecclestone suggests that critical autonomy can be developed "through engaging with established bodies of thought, being able to participate in associated conversations, seeing new possibilities for understanding and being able to go beyond conventional insights and wisdom and where learners can develop new knowledge from old or participate in determining the content of learning or what counts as educational knowledge."

Assessment tasks in the first three papers require RTLB to write both academic essays and reports of casework in which they must demonstrate an understanding of certain theoretical knowledge, the literature that informs their practice and how they are applying aspects of this knowledge to their work. In terms of Ecclestone's framework, these tasks could be expected to promote both procedural and personal autonomy. The challenge for the consortium was to design assessment measures that would be likely to promote critical autonomy. The portfolio was seen as providing support for the development of both procedural and personal autonomy, and as having the potential to promote critical autonomy also.

From the diverse range of interpretations of the term prevalent in the literature, the following was the definition chosen for the portfolio in this programme.

A portfolio is a selective collection of teacher work gathered across diverse contexts over time, framed by reflection and enriched through collaboration that has as its aim the advancement of teacher learning. (adapted from Wolf \& Siu-Runyan, 1996, p. 31)

This definition can be seen to mirror several of the above features included by Ecclestone as supporting the development of critical autonomy. The RTLB are required to select evidence from their real work, thus having the autonomy to decide what they believe "counts 
as educational knowledge." The reflection on the evidence they select should encourage RTLB to "see new possibilities for understanding" and to "go beyond conventional insight and wisdom." Collaboration with colleagues, faculty and supervisors will provide "the associated conversations."

In considering the portfolio, the consortium was not only concerned to develop a process that would promote effective learning and practice but also one that would assist teaching staff to make a sound assessment of RTLB practice in relation to the programme outcomes. The use of portfolios in education has grown in response to the search for methods of assessment that are more appropriate to a constructivist view of learning and teaching (Shaklee, Barbour, Ambrose \& Hansford, 1997). This view is encapsulated in the following statement by Loacker and Mentkowski (cited in Banta, 1993), when writing about the philosophy of assessment at Alverno College, a university that pioneered portfolio assessment. "Education means being able to do what one knows. Inherent in this principle is the concept that learning outcomes for students are abilities students develop in order to use the knowledge they have constructed" (p. 7). The consortium saw the portfolio as enabling the RTLB to engage in a meaningful interaction between the course content and their practice, and to present the results of that interaction for assessment.

Paulson, Paulson and Meyer (1991) maintain that portfolios enlarge the teacher's view of what is learned and allow faculty to view teachers in a broader context than do traditional assessment methods. They go further and suggest, "If carefully assembled, portfolios become an intersection of instruction and assessment" (p. 61) providing a process in which the teacher "is a participant in, rather than an object of, assessment" (p. 63). Lyons (1998) uses the phrase "authoring one's own learning" (p. 3) as an idea fostered by portfolio development. This altered relationship between assessment and instruction is a crucial element of the portfolio process with all the characteristics of performance, if not authentic assessment (i.e., meaningful, significant and worthwhile tasks involving observable performance, clear standards, reflection and transfer).

The extensive use of portfolios has emerged from the school reform movement in the USA in the 1980s (Lyons, 1998). Shulman (1998) and colleagues on the Stanford Teacher Assessment project began exploring assessment methods that would capture the complexity of teaching. One of the challenges such a project faces is that what comprises the professional knowledge of teaching is problematic. Eraut (1994) argues that while there is a technical body of knowledge that can be codified (e.g., educational theory, curriculum knowledge) much of what teachers do is based on knowledge that is both expressed and learned through practice. Eraut suggests that these different types of knowledge are integrated in professional performance and therefore difficult to unravel. Assessment tasks such as tests and essays are valuable for assessing relatively isolated pieces of knowledge, but are not well-suited to accessing the kinds of process that occur during the actual teaching experience. Classroom observations and assessment centre tasks, while tapping real teaching practice, are limited by issues of sampling and authenticity, respectively (Shulman, 1998). Taking the analogy of an artist's portfolio, Shulman and his colleagues developed the notion of a teaching portfolio.

In addition to meeting the demands of complexity, Shulman (1998) requires that teacher assessment take account of another requirement; consequential validity. He states that, "any form of teacher assessment has to meet a new standard: that the manner in which it is deployed improves the quality of teaching and opportunities for becoming a better teacher" (p. 30). He considers that the portfolio meets this second requirement also.

So, in the portfolio, the consortium saw the opportunity to both promote RTLB learning and effective practice and to assess this learning and practice in a way that could overcome the limitations of other, more traditional assessment methods, and would recognise the legitimacy of workplace learning (Retallich \& Groundwater-Smith, 1999).

In attempting to meet both these requirements, the consortium proposed that the portfolio would be both a process (to foster professional learning and practice) and a product (to enable assessment of the RTLB achievement in the programme).

\section{Process}

During the year, six to eight seminar days were conducted on which each class of RTLB met with their lecturer and colleagues. The purpose of these days was to ensure that RTLB understood what was required in the portfolio and were supported both by their lecturer and colleagues in this development. At these meetings lecturers made presentations and screened a video made specifically to illustrate the peer coaching process. A variety of readings about portfolios, peer support methods and reflective practice were supplied and discussed 
and a range of activities were presented to:

1. ensure a clear understanding of what a portfolio was

2. explain the requirements for the completed portfolio;

3. identify descriptors ${ }^{1}$ that operationalized each of the outcomes that the portfolio was to demonstrate;

4. establish support systems such as critical friends, peer coaches, mentors;

5. critically examine evidence;

6. reflect on evidence and the work to which it relates; and

7. share annotated evidence with colleagues.

The process of developing a portfolio was explained as having four aspects.

\section{Collection}

Throughout the year RTLB collected a range of material that arose from their work and study to be used in their portfolio as evidence.

\section{Selection}

With the support of colleagues, RTLB selected from the material collected that which they considered to be the most suitable to demonstrate that they had met the outcomes of the programme. The process of selection involved RTLB in deciding on the best evidence in terms of clarity, sufficiency, quality, reliability and validity.

\section{Annotation}

Once selected, the evidence was annotated by RTLB to explain what it was, of what it was evidence, and why.

\section{Reflection}

At the beginning of the year the RTLB were asked to write a personal theory statement. This was described as their own developing perspective derived from their knowledge, understanding, philosophy and experience relevant to their professional practice. They were asked to consider such issues as how children learn, the role of the teacher and RTLB, the purpose of education, and the significance of the Treaty of Waitangi. RTLB were invited to submit this statement to their lecturer who took the role of a critical friend in commenting on the statement. The RTLB were encouraged to review and refine this statement as the portfolio process progressed and were required to submit the original and the revised personal theory with the portfolio. In this way RTLB were being encouraged to make explicit their often tacit beliefs, knowledge and values so as to be able to reflect on how this influenced their practice, to what extent their practice was consistent with their espoused theory, and the potential for conflict between their world view and that of others with whom they work.

At the time of writing the first personal theory statement, RTLB were also encouraged to consider one or two professional development goals that they considered they would need to achieve if they were to reach the competency to gather the necessary evidence for the portfolio. This was intended to help the RTLB identify areas for growth that they regarded as important to achieve the outcomes of the course.

During the process of selection of evidence to compile the final portfolio, RTLB shared material with others, discussing the experiences that related to the evidence and the rationale for its selection. In the process of annotating the evidence they were asked to consider the relationship of the evidence to the content of the programme, their personal theory, and personal goals. RTLB were introduced to a number of approaches to reflection, including Dewey (1910), Schõn (1983), Zeichner and Liston (1996) and Van Manen (1977).

RTLB were encouraged to establish critical friend or peer coaching relationships and to meet these peers for support between training days (Costa \& Kallick, 1993; Garmston, Linder \& Whitaker, 1993; Showers, 1985). All RTLB also had the opportunity to meet in groups with a professional supervisor employed by the Specialist Education Service. Lecturers were also available to meet with RTLB and/or to review material submitted for comment.

In addition to the training days RTLB attended, they also had a half day of study leave per week throughout the year. Some of this time was used by RTLB to meet with colleagues to discuss portfolio development, as well as to work individually on compiling of evidence.

\section{Product}

Finished portfolios consisted of six to eight sets of evidence. Evidence took a number of forms, as suggested by Barton and Collins (1993) - for example, items produced during the normal course of RTLB work (e.g., records of meetings, observations, interviews, case notes, planning forms, I.E.Ps, samples of student work, monitoring records from teachers); items about RTLB work that are not normally captured, (e.g., transcripts of interviews, photographs), documents about RTLB work written by others; and documents specifically prepared for the portfolio (e.g., case reports, statements of personal philosophy, reflective statements). 
The completed portfolio consisted of six parts:

1. A brief statement of the context in which the RTLB works;

2. The first draft and the final statement of the personal theory that underpins their work;

3. Six to eight sets of evidence to demonstrate that they have met the outcomes of the programme, annotated appropriately. They could choose how to compile these sets of evidence. They could, for example, have a set of evidence for each of the outcomes of the programme, or present sets of evidence that relate to specific projects, e.g., work with one teacher, a staff development programme undertaken in a school, or a project such as a school-wide peer tutoring project. In this case the evidence needed to be annotated to make explicit which learning outcomes each set was supporting.

4. One or two of these sets of evidence must demonstrate the RTLB's efforts to recognise and promote the bicultural nature of the New Zealand education system, and to ensure equitable educational opportunities and outcomes for Maori students.

5. A concluding statement that draws all the elements of the portfolio together.

6. A reference list.

\section{Potential tensions}

When designing the portfolio and the process for its development by RTLB the consortium was aware of a number of potential tensions, based on a review of the literature, and prior experience (Jones, 1999).

The first of these related to the issue of ownership of the process.

Because RTLB select evidence and reflect on this evidence, the portfolio becomes a unique expression of their understanding and skill. However ownership can be a key issue for both faculty and learners (Carroll, Potthoff \& Huber, 1996). The challenge is to strike a balance between the imposition of structure that may be perceived as necessary by the faculty who need to assess the portfolio against the prescribed criteria, and the opportunity for choice and personal goal setting that enables the RTLB to perceive the portfolio as a tool for professional growth.

A second and related possible tension relates to the purpose of the portfolio. There is potential for difficulty when purposes for the portfolio are in conflict (Paulson et al, 1991). If RTLB perceive the portfolio as being primarily a task to meet the requirements for high stakes assessment they are likely to demand a high level of prescription so that they can "get it right". Faculty who wish to see the portfolio as a tool for promoting RTLB responsibility for their own learning, as a means of engaging the teachers in a process of self assessment and reflection and as an opportunity for them to express their individuality are likely to resist the request. A decision was made that, although considerable scaffolding would be provided during the course, no models of portfolio items would be provided. The faculty rationale for that decision was that providing a model would encourage the view that there was a right or preferred way to complete the portfolio and would discourage originality and individuality. However it was predicted that this absence of a model would be the source of some disquiet among some RTLB.

A major potential for tension was predicted among those RTLB who, either from professional preference or the restrictions of their work situation, were not working in the inclusive model. It was predicted that these people would have difficulty collecting sufficient evidence to meet the requirements of the portfolio, and could generate high levels of anxiety and hostility to the process. Likewise it was predicted that those RTLB who had not achieved sufficient levels of competence in the areas assessed by the portfolio would have similar responses.

For the portfolio process to result in transformational learning, there is a need for RTLB to achieve critical autonomy. Studies such as those of Korthagen and Wubbels (1995) and LaBoskey (1993) suggest significant individual variation in the willingness or ability to engage in reflection. LaBoskey finds support for Dewey's proposal that attitudes of openmindedness, responsibility and wholeheartedness are integral to reflective action. Fewer than half the RTLB have been directly selected for their present position, and all are undertaking this course as a compulsory requirement of their job. It could therefore be expected that issues of personal suitability and motivation may have a significant impact on the degree to which individuals achieve critical autonomy. Ecclestone (n.d.) identifies an important relationship between intrinsic motivation and the drive for autonomy. For those RTLB who feel coerced into this training and are completing it without perceiving it to be of any value to their personal or professional growth, it seems probable that their engagement in the portfolio process will not be sufficient to achieve critical autonomy. 


\section{Outcomes to Date}

After the first cohort of RTLB have completed their portfolios, we have an indication of what has helped and hindered the portfolio process, and also of how the development of the portfolio is impacting on the work of the RTLB. Data have been gathered from: evaluations completed by RTLB at the end of each teaching block; focus group and individual interviews with 20 RTLB; conversations with RTLB; and analysis of concluding statements in a selection of portfolios. At this stage it is clear that there is considerable diversity of view among the RTLB, both about the process and its impact on practice. On almost every issue there are opinions at both ends of the spectrum.

\section{What has helped or hindered the process}

Many RTLB have reported anxiety about the task throughout the year. For some this anxiety soon passed. For others it continued. There appear to be several reasons for the high levels of anxiety.

There has been a considerable difference among RTLB as to the time it has taken to understand the requirements of the portfolio and get started on the process of selecting, annotating and reflecting on evidence. While some were clear and confident quite early in the year, others report that only by about July or August did they fully grasp the meaning of evidence and the process of annotation. Many report that the opportunity to view models of portfolios would have helped this understanding.

The size of the task has been reported by some to have been daunting. However, once started, most report that keeping within the word count has been challenging. Some have found this so problematic that it has been a major cause of stress.

Time has been a frequently mentioned concern. Some found the process of annotating evidence very time consuming, especially if they decided after completing a piece or set of evidence that they are not satisfied with it. The sense that the task would never be finished has been expressed by some. Some reported that the portfolio was always with them, that they could not get away from it, could not stop thinking about it, woke up in the night thinking about it, and other expressions indicating that it was a prominent part of their lives. For some this has been overwhelming. Others, however, said that they had developed ways of using these thoughts constructively, for example investing in a dictaphone to record thoughts while travelling in the car, or keeping a journal to record ideas and reflections. For some who were slow in beginning the process, a sense of panic developed as the due date approached. For others, the nearing of the deadline was the pressure they needed to galvanise their efforts. University staff have also found that the time needed to provide support and critical comment on material far exceeded the requirements of a normal university course.

Another source of anxiety has been identified by RTLB who report that they have been made uncomfortable by the process, because it has highlighted the ideal for RTLB practice and constantly alerted them to the discrepancy between that and their practice. Others have identified stress relating to the paradigm change. They are concerned that much of their work does not reflect the role of the RTLB as indicated by the course outline. This has been a particular source of stress for those RTLB who are teaching in special classes, but has also been expressed by those who are in itinerant positions. Other RTLB however have stated that being pushed out of their comfort zone has taken them to a higher level of learning.

While some RTLB reported that the portfolio process highlighted ways in which they were working that were inconsistent with the inclusive paradigm, others reported that the process helped them to clarify their role and be more assertive about refusing requests to undertake work they considered inappropriate to their role or expertise.

Another issue of concern for some has been about the presentation of their portfolio. One RTLB asked, "Is it the art of work or work of art?" Some felt that they had spent too much time trying to decide on the format, or perfect their presentation at the expense of the content. Others have found that sharing ideas about format and presentation has been helpful in clarifying their thinking.

The role of colleagues has played a significant part in the process for most RTLB. Most report that working with colleagues as critical friends or peer coaches has enhanced the focus of collegial support. Some RTLB report that working in this way on the portfolio has developed a greater sense of unity in their cluster group about shared values, beliefs and perception of their role. Sharing with others on training days, at supervision sessions or in self-selected study groups has been helpful to many in increasing their understanding of the task and in providing valuable feedback on their work. Given the high level of stress of some RTLB about the portfolio, meetings with other colleagues have, at times served as a forum for sharing anxiety and have resulted in increasing stress levels. In some groups, the use of Email appears to have had a similar effect. 
The support of university staff and supervisors has been identified by many as very helpful. However some RTLB perceive feedback from these sources as a demand for perfection or as implication that there is a "correct" way to do things. Faculty and supervisors have noted that discussions with RTLB about their work for the portfolio have often been very thoughtful and professional.

\section{Impact on competence}

Apart from the impact of anxiety and time pressures, RTLB have reported no other ways in which the portfolio process has impacted negatively on their work. There are RTLB who saw the process as of no particular relevance to their work. Some saw it as an onerous task that they needed to complete to finish the course. However, others reported that they found the process stimulating, enjoyable and rewarding. The benefits they report are all related to ways in which they believe the process has improved their work.

One aspect of this has been the way in which the portfolio has helped to link theory and practice. Annotating and reflecting on evidence has required a revisiting of lecture notes and course reading material as well as further reading of relevant literature. This has had several effects. It has increased the relevance of theoretical material on the programme to actual practice. It has affirmed RTLB in the appropriateness of their practice and increased their confidence in what they do and their readiness to advocate for the practices they believe are effective. It has also provided a review of material covered that they had not fully "taken on board" and encouraged them to enhance their practice as a result.

Having to select evidence for the portfolio has been reported as having several positive impacts on practice. In order to be able to collect evidence RTLB report that they have needed to improve their record keeping, and they see that has improved professionalism. Others report that, in an effort to be able to demonstrate a high level of competency for their portfolio, they have "gone the extra mile" to improve their practice. Examples given include taking the time to: develop new forms for interviews to ensure that the collaborative consultation process is followed carefully; prepare and plan carefully for meetings so that the outcomes are more productive; and introduce new practices into programmes that they might not have got around to so as to ensure that they are able to demonstrate a range of effective inclusive teaching strategies in their portfolios.
Another major theme in relation to improved competence is that of reflective practice. RTLB report that they are now more thoughtful in their approach to their work. While most RTLB state that they have always reflected on their work in the past, they now believe that they do this more precisely and specifically. The added depth and structure of reflection is attributed by some RTLB to the process of writing, reading and reworking the writing. Having a structure for reflection has made some more aware of their reflection and increased their confidence about their role and the ethical and professional challenges they face.

It has also increased their level of personal insight. RTLB report that they are now more honest about themselves and therefore also more realistic. Personal theory has become more explicit during the portfolio process. Many report that the personal theory written at the beginning of the paper was approached as an academic exercise but as the year progressed they were much clearer about what they believe and why. In some cases people report that they have entirely rewritten their first statement and others say that they have affirmed and expanded on what they wrote.

Another outcome of the requirement for reflection in the portfolio process is that some RTLB say that they think it has given legitimacy to reflection as a necessary element of their practice and that time given to this was not only justified, but necessary.

Those who have been working regularly with colleagues on their portfolio say that this has enhanced the role of collegial support or supervision in their work. They say that they feel that there is more professional focus and positive benefit from these meetings.

\section{Conclusion}

Until the completed portfolios from the second cohort of RTLB have been submitted and analysed at the end of 2001 it is not possible to draw any final conclusions about the extent to which the portfolio has achieved the hoped-for impact on RTLB professional development. Interim results suggest, however, that the answer will be "... that it has for some and not for others."

All the predicted tensions are indicated in the interim results. So too are the hoped for outcomes. Faculty and many RTLB see this year as having been a challenging but exciting and worthwhile journey, one on which much has been discovered about the demands of this process. Equally there have been valuable discoveries about the skills needed to 
work as a competent RTLB, the benefits of collegial support, and the value of theory and analytical reflection. Shulman (1998) describes developing a portfolio this way: "What is declared worth documenting, worth reflecting on, what is deemed portfolio-worthy, is a theoretical act" (p. 24). At the beginning of the year RTLB were asked to explain what they thought Shulman meant. Many were unsure; they would not be today!

\section{Notes}

1. All RTLB groups completed brainstorm activities to develop descriptors for each learning outcome and these were collated nationally, distilled and issued to the RTLB early in the year.

\section{References}

Anderson, R., \& DeMeulle, L. (1998). Portfolio use in twenty-four teacher education programmes. Teacher Education Quarterly, 25(1), 23-31.

Banta, T., \& Associates. (1993). Making a difference: Outcomes of a decade of assessment in higher education. San Francisco: Jossey Bass.

Barton, J., \& Collins, A. (1993). Portfolios in teacher education. Journal of Teacher Education, 44(3), 200-210.

Carroll, J., Pothoff, D., \& Huber, T. (1996). Learnings from three years of portfolio use in teacher education. Journal of Teacher Education, 47(4), 253-262.

Costa, A.,\& Kallick, B. (1993). Through the lens of a critical friend. Educational Leadership, 51, 49-51.

Dewey, J. (1910). How we think. Boston: D.C. Heath \& Co.

Ecclestone, K. (n.d.) Assessment and critical autonomy in post compulsory education. Unpublished manuscript.

Eraut, M. (1994). Developing professional knowledge and competence. London: Falmer Press.

Garmston, R., Linder, C., \& Whitaker, J. (1993). Reflections on cognitive coaching. Educational Leadership, 51, 57-61.

Glynn, T. (1998, July). A collaborative approach to teacher development: New initiatives in special education. Paper presented to Australian Teacher Education Association 28th Conference, Melbourne, Australia.

Jones, E. (1999). Discussion paper on the purpose of a portfolio in the RTLB professional development programme. Un published paper prepared for Universities' Consortium Management Committee.

Korthagen, F., \& Wubbels, T. (1995). Characteristics of reflective practitioners: Towards an operationalisation of the concept of reflection. Teachers and Teaching: Theory and Practice, 1(1), 51-72.

LaBoskey, V. (1993). A conceptual framework for reflection in pre-service teacher education. In J. Calderhead \& P. Gates (Eds.), Conceptualising reflection in teacher development (pp. 23-38). London: The Falmer Press.

Ladbrook, J., \& Middleton, S. (1997, December). Portfolios: Promoting the role of reflection in the pre-service education of graduate teachers. Paper presented at NZARE conference, Auckland.

Lyons, N. (1998). Portfolio possibilities: Validating a new teacher professionalism. In N. Lyons (Ed.), With portfolio in hand: Validating the new teacher professionalism (pp. 1-21). New York: Teachers College Press.

Paulson, F., Paulson, P., \& Meyer, C. (1991). What makes a portfolio a portfolio? Educational Leadership, 48(5), 60-63.

Retallick, J.,\& Groundwater-Smith, S. (1999). Teachers' workspace learning and the learning portfolio. Asia-Pacific Journal of Teacher Education, 27(1), 47-59.

Schõn, D. (1983). The reflective practitioner: How professionals think in action. New York: Basic Books.

Shaklee, B., Barbour, N., Ambrose, R., \& Hansford, S. (1997). Designing and using portfolios. Boston: Allyn \& Bacon.

Showers, B. (19985). Teachers coaching teachers. Educational Leadership, $42,43-48$.

Shulman, L. Teacher portfolios: A theoretical activity. In N. Lyons (Ed.), With portfolio in hand: Validating the new teacher professionalism (pp. 23-49). New York: Teachers College Press.

Sutton, R. (2000, July 14). What we did in the holidays. Education Review, p. 16.

Van Manen, M. (1977). Linking ways of knowing with ways of being practical. Curriculum Inquiry, 6 (3), 205-228.

Wolf, K., Lichtenstein, G., \& Stevenson, C. (1997). Portfolios in teacher education. In J. Strange(Ed.), Evaluating teaching: A guide to current thinking and best practice (pp. 193-214). California: Corwin Press.

Wolf, K., \& Siu-Runyan, Y. (1996). Portfolio purposes and possibilities. Journal of Adolescent and Adult Literacy, 40(1), 30-37.

Zeichner, K., \& Liston, D. (1996). Reflective teaching: An introduction. Mahwah, NJ: Lawrence Erlbaum Associates.

\section{The author}

Elizabeth Jones is a lecturer in the RTLB professional development programme at Victoria University of Wellington. She has worked for the last six years in teacher education. She has worked in New Zealand education since 1976 and has been a teacher, primary school principal and psychologist. 